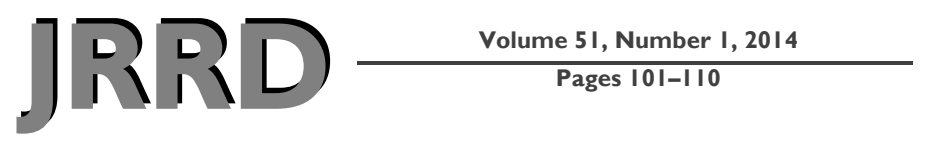

\title{
10Pressure casting technique for transtibial prosthetic socket fit in developing countries
}

\author{
Peter Vee Sin Lee, PhD; $;^{*}$ Noel Lythgo, PhD; ${ }^{2}$ Sheridan Laing, BEng; ${ }^{1}$ Jimmy Lavranos, BSc; $^{3}$ Nguyen Hai \\ Thanh, BSc ${ }^{4}$ \\ ${ }^{1}$ Department of Mechanical Engineering, Melbourne School of Engineering, University of Melbourne, Parkville, Victoria, \\ Australia; ${ }^{2}$ School of Medical Sciences, Royal Melbourne Institute of Technology University, Melbourne, Victoria, Australia; \\ ${ }^{3}$ Prosthetics and Orthotics, Royal Children's Melbourne Hospital, Melbourne, Victoria, Australia; ${ }^{4}$ Vietnamese Training \\ Centre for Orthopaedic Technologists, Hanoi, Vietnam
}

\begin{abstract}
This study investigated a low-cost and low-skill dependent pressure casting technique (PCAST) to fabricate and fit transtibial (TT) prosthetic sockets in a developing country. Thirteen adult volunteers (average age $47 \mathrm{yr}$ ) with unilateral TT amputation participated. After fitting, five participants were lost to follow-up (four rejected the prosthesis and one died). The eight remaining participants used the prosthesis for an average of $167+/-1 \mathrm{~d}$ and indicated regular use throughout this period. Success was evaluated by measures of satisfaction (Satisfaction with Prosthesis Questionnaire [SATPRO]), physical function, and gait recorded after fitting and following the usage period. SATPRO results showed high levels of satisfaction on both occasions. After the usage period, the timed upand-go and six-minute walk performances increased by $1.7+/-$ $2.0 \mathrm{~s}$ and $60+/-29 \mathrm{~m}(p=0.001)$, respectively, whereas gait speed, cadence, step and stride length, support base, and percent gait cycle times remained unchanged. The results show that a TT PCAST socket (with some minor modifications) was successfully fitted to eight of the participants (success rate of $62 \%)$. It is reasonable to conclude that this technique may assist people with TT amputation in a developing country where there is a lack of trained personnel. Importantly, this technique may reduce TT prosthetic costs and increase fitting opportunity in a developing country.
\end{abstract}

Key words: amputee, biomechanics, gait, low-cost, patient satisfaction, pressure casting, rehabilitation, residual limb, socket, socket fit, transtibial amputation.

\section{INTRODUCTION}

The mobility and physical function of a person with unilateral transtibial (TT) amputation is highly dependent upon the fit of the prosthetic socket. It dictates the comfort of the prosthesis, a major concern for people with lowerlimb amputation [1]. Although fundamental prosthetic principles are used to create and fit a socket, successful fittings are largely dependent on the skill, knowledge, and experience of the prosthetist. In addition, socket refit or replacement is a common problem even in developed countries with excellent clinical support and advanced

\footnotetext{
Abbreviations: $\% \mathrm{GC}$ = percent gait cycle, $6 \mathrm{MWT}=$ six-minute walk test, ICRC = International Committee of the Red Cross, ISPO = International Society for Prosthetics and Orthotics, PCAST = pressure cast, $\mathrm{PTB}=$ patellar tendon bearing, RMMANOVA = repeated-measures multivariate analysis of variance, SATPRO = Satisfaction with Prosthesis Questionnaire, $\mathrm{SD}=$ standard deviation, $\mathrm{TT}=$ transtibial, TUG = timed up-andgo, VIETCOT = Vietnamese Training Centre for Orthopedic Technologies.

*Address all correspondence to Peter Vee Sin Lee, PhD; Associate Professor, Department of Mechanical Engineering, University of Melbourne, Victoria, 3010, Australia; +61-3-83444426; fax: +61-8344-4290. Email: pvlee@unimelb.edu.au http://dx.doi.org/10.1682/JRRD.2012.10.0191
} 
prosthetic devices. Datta et al. studied 104 people with TT amputation over a $10 \mathrm{yr}$ period and found that they needed an average of 6.25 socket refits [2]. A later study by Nair et al. also showed that 73 people with TT amputation needed an average of 2.9 new sockets over a $10 \mathrm{yr}$ period [3].

Many challenges are faced by large numbers of people with lower-limb amputation in developing countries such as Vietnam. Foremost are cost and access to skilled prosthetic services. Currently, a successful socket fit involves significant prosthetist input because the socket cast is shaped by hand. This is labor intensive and largely dependent upon skill, knowledge, and experience [4-6]. For these reasons, several attempts have been made to develop a socket fabrication technique that requires little or no prosthetic skill. A method that shows potential is the pressure casting technique. This technique produces a socket cast through the application of air, sand, or water pressure to plaster wrapped over the residual limb.

A sand-based casting method (Center for International Rehabilitation) has been investigated [6] but was found to be of limited utility in developing countries because it required a trained prosthetist and a ready source of electrical power. Earlier studies [4-5] have investigated a waterbased pressure cast (PCAST) socket. Another study compared the performance of a PCAST socket with a conventional hand-cast patellar tendon bearing (PTB) socket by recording residual limb-socket interface pressures in four adults with unilateral TT amputation [7]. Although the sample size of the study was small, it found the PCAST socket fit to be as successful as the PTB socket fit. However, a main limitation of this study was participants were not tested on PCAST sockets that were prescribed for normal daily activities. Instead, these sockets were modified with pressure transducers housing for laboratory-based testing only; i.e., participants did not have the opportunity to wear the PCAST socket outside the laboratory for an extended period. The study also did not assess other functional outcomes such as participant's satisfaction and improvement in gait due to extended socket usage in realistic daily activities. Finally, the laboratory sockets were produced using modern facilities and fitted with contemporary prosthetic components such as the Endolite Multiflex foot systems (Blatchford, United Kingdom). These conditions therefore negate the applicability of the results for the PCAST to be used in developing countries. Although the PCAST potential lies mainly in a developing country setting, no studies have yet to be conducted under such an environment. The aim of this investigation was therefore to determine whether the PCAST can produce a comfortable socket, determined by measures of satisfaction, physical function, gait, and period of usage, in a developing country setting using low-cost International Committee of the Red Cross (ICRC) lowerlimb prosthetic components (polypropylene technology).

\section{METHODS}

\section{Participants}

Thirteen volunteers with unilateral TT amputation classified as active prosthesis users were recruited from the Vietnamese Training Centre for Orthopedic Technologies (VIETCOT) (Hanoi, Vietnam). Information about skin, state of tissue, circulation, and presence of anomalies and the participants' level of activity (Medicare Functional Classification Level, or K-level) were recorded (Table 1) [8]. The participants' descriptive statistics are listed in Table 1, including mean \pm standard deviation (SD) age of $47.2 \pm 16.0 \mathrm{yr}$ and amputation duration of $25.7 \pm 14.4 \mathrm{yr}$.

\section{PCAST Socket}

VIETCOT staff with International Society for Prosthetics and Orthotics (ISPO) category II qualifications fabricated and fitted the prostheses [9]. A cotton sock was placed over the participant's residual limb, followed by a plaster wrap from the knee epicondyles to the distal end (Figure 1). The participant then stood with the intact limb on a weighing scale and placed the residual limb into a plastic bag-type diaphragm housed in a cylindrical tank. The tank was filled with water through a tap located on the tank and hose connected to water mains. The tap was turned off once the participant was able to stand normally, without any aid, with half-body weight supported by pressurized water. This was achieved by first having the participant stand on a weighing scale with his or her intact leg, then slowly transferring weight to the residual limb onto the diaphragm in the tank. The pressure in the tank was adjusted by letting water in and out of the tank to match the weight applied by the residual limb until a normal and level standing position was achieved by the participant. Level standing was ensured by checking the heights of the participant's right and left iliac spines. Upon level standing, the weighing scale would register approximately half the participant's body weight. Once the plaster wrap hardened, the tank was depressurized and the plaster removed. A positive plaster model was 
Table 1.

Participant details $(n=13)$.

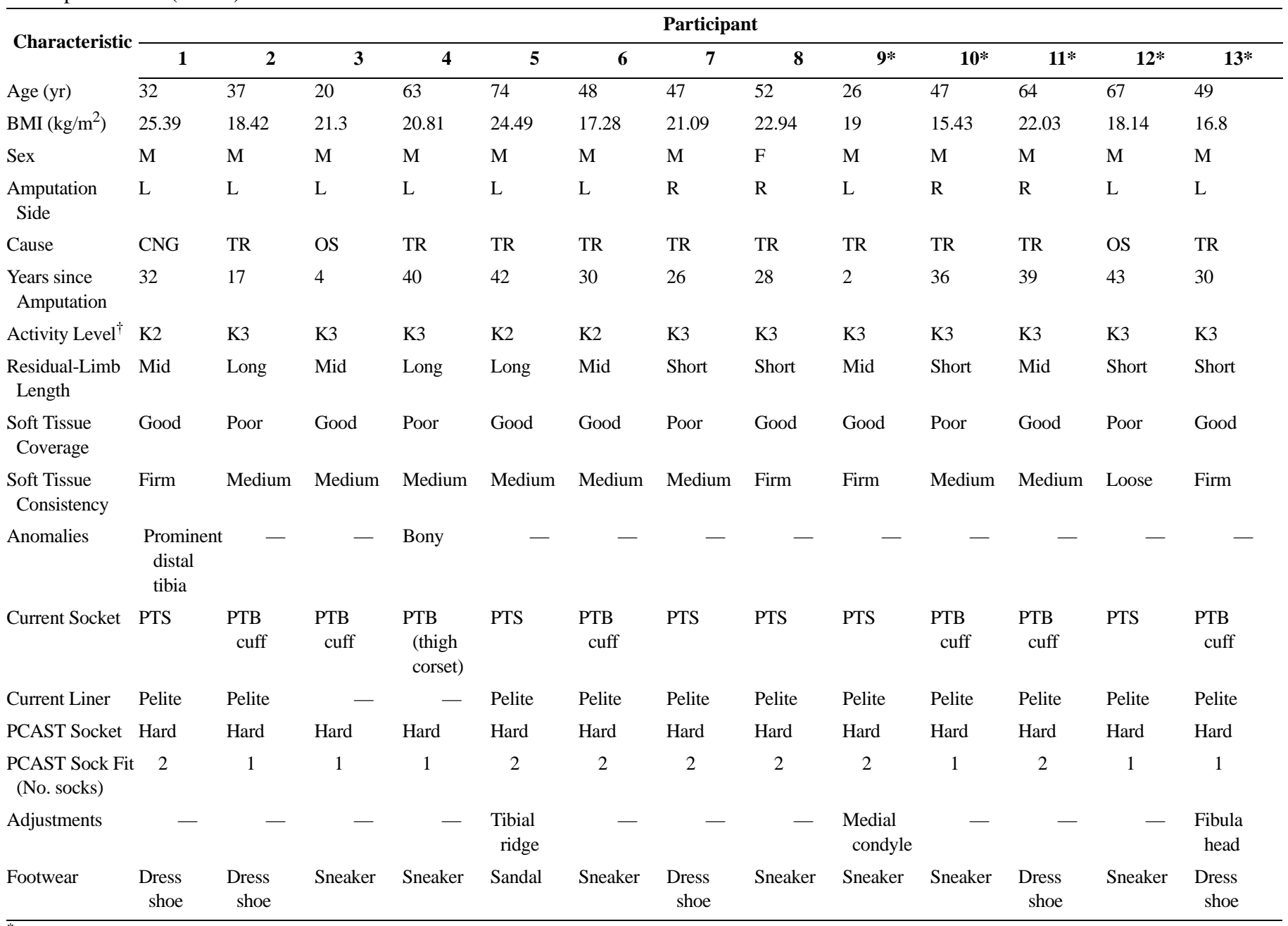

${ }^{*}$ Lost to follow-up.

${ }^{\dagger}$ Medicare Functional Classification Level, or K-level.

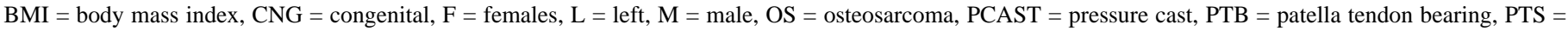
patella tendon supracondylar, $\mathrm{R}=$ right, $\mathrm{TR}=$ trauma.

made from the negative wrap and obvious rough or anomalous edges/ridges were removed. The socket was then fabricated by building a distal pelite cap to allow for inner socket length adjustability during fitting. This was dependent on the tolerance level of the participant. A polypropylene hard socket was then molded from the cast. Trimlines were cut down anteriorly midpatellar level, posteriorly to the popliteal fossa and medially and laterally just below the epicondyles. The socket was then attached to low-cost ICRC prosthetic components and a rubber foot [10]. The alignment setup was kept intuitive with the sagittal plane midline over the posterior third of the foot and the coronal plane midline through the center of the heel. Cuff suspension was used by the participants. The only soft interface between the residual limb and socket was cotton socks of the same thickness used in the casting process (Table 1). Distal end discomfort was controlled by removing the distal pelite pad to create an open-ended socket. The casting process, socket fabrication, socket fitting, and prosthesis alignment were undertaken by the same VIECOT staff with ISPO category II qualifications.

Fundamentally, the PCAST involves low skill because little or no rectification to the positive socket mold is needed. Nonetheless, some minor adjustments (Table 1) may be needed to relieve pressure sensitive areas. The only 


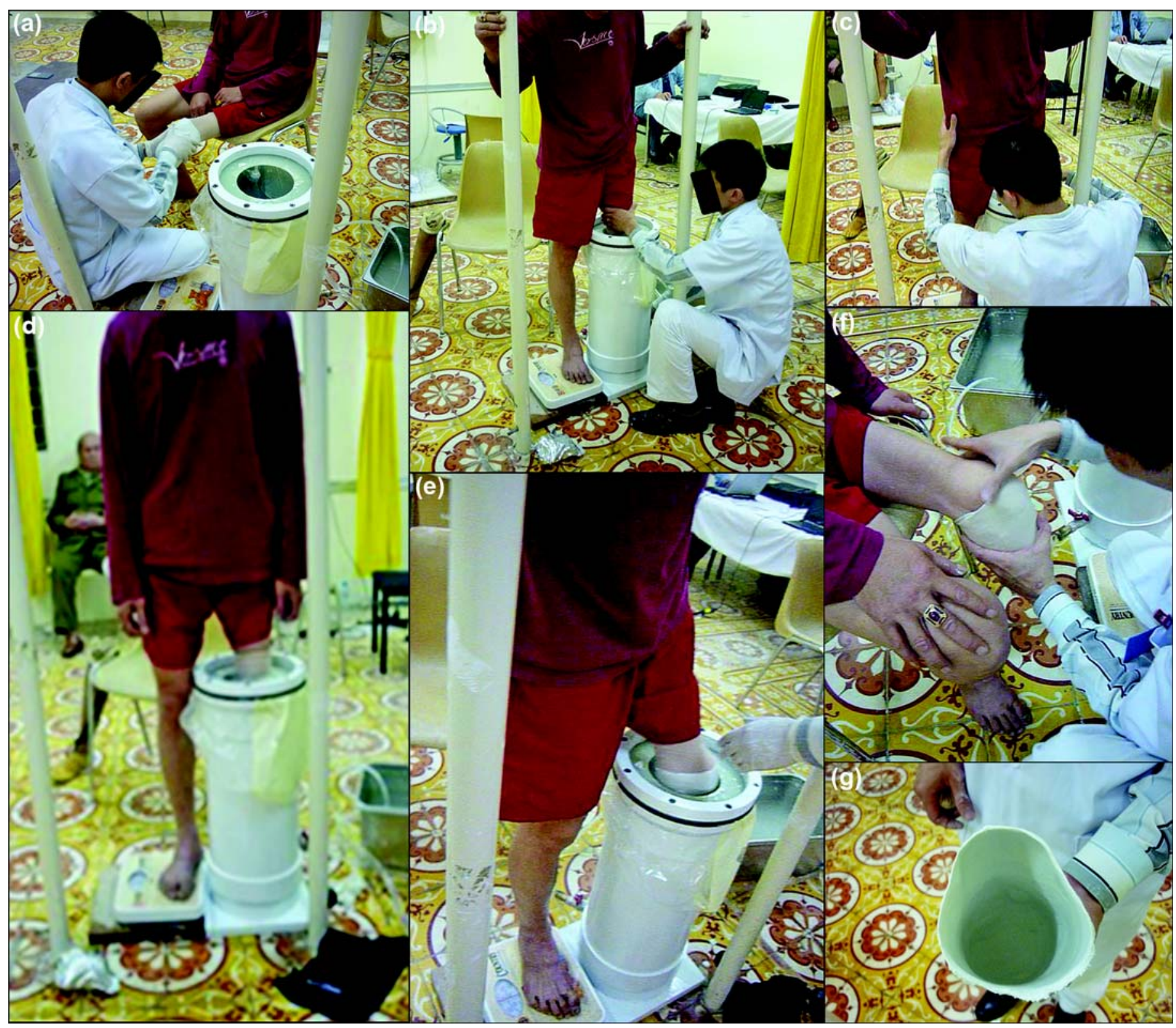

\section{Figure 1.}

(a) Plaster wrap cast. (b) Participant inserts residual limb into pressure cast (PCAST) tank. Limb is placed into plastic diaphragm and pressurized with water. (c) Participant stands normally. (d) Intact and residual limbs support half-body weight each. Intact limb support measured by weight scales. (e) PCAST tank is depressurized and participant's residual limb is removed. (f) Hardened plaster cast is removed. (g) Plaster cast is used to produce socket without any shape rectification.

adjustments allowed were to soften the socket with a heat gun and expand its volume with simple tools. Dynamic alignment was performed as per usual by the category II prosthetists. Throughout the usage period, the participants were under no obligation to use the prosthesis and could replace it with their original prosthesis at any time.
Once the participants indicated satisfaction with the prosthesis, and following a short acclimatization period (about $15 \mathrm{~min}$ ), the following tasks were completed in the order listed: timed up-and-go (TUG), six-minute walk test (6MWT), gait trials, and satisfaction questionnaire. These tasks were also completed after an extended usage period. 
Each participant wore dress shoes, sandals, or sneakers, with the same footwear worn on each test occasion.

\section{Physical Function}

The 6MWT and TUG have been used to measure function in populations with lower-limb amputation [1114]. The instructions for the 6MWT were "walk at normal or comfortable speed." A familiarization "lap" was completed and then distance recorded. The instructions for the TUG were "complete the task as quickly as possible." Time was recorded by a stop watch. An initial practice was followed by three test trials, with a 1 to 2 min rest between trials. The average time was used in the analysis.

\section{Gait}

A GAITRite (CIR Systems Inc/GAITRite; Sparta, New Jersey) instrumented walkway (457 cm long, $80 \mathrm{~Hz}$ ) recorded gait speed, cadence, step length, stride length, support base, single support time, double support time, stance time, step time, and stride time. The walkway was placed on a flat surface with an approach and departure distance of 2 to $3 \mathrm{~m}$ [15]. The same assessor collected the data. Participants completed two practice walks followed by six walks at self-selected speed. The instructions were "walk at normal or comfortable speed." Average gait data was calculated for each participant and used in the analysis.

\section{Satisfaction with Prosthesis Questionnaire}

The participants completed the Satisfaction with Prosthesis Questionnaire (SATPRO) [16]. This has high internal consistency and test-retest reliability [16-17]. It has a number of questions about prosthesis fit and comfort. There are questions that assume the socket has been used for a long period. Given that participants received the socket within a day, these questions were omitted from the initial analysis but were included in the postusage period analysis.

\section{Data Analysis}

Descriptive statistics were calculated. Data sets were assessed for normality by measures of skewness and kurtosis. Three-way repeated-measures multivariate analyses of variance (RMMANOVAs) with contrast testing (twotailed) were used to compare pre- and postusage period data. Three separate RMMANOVAs were conducted on the (1) physical function and SATPRO data, (2) spatial gait data, and (3) temporal gait data. Statistical calculations were performed with SPSS (version 17, IBM Corporation; Armonk, New York), with the alpha level set at 0.05.

\section{RESULTS}

All data sets were found to exhibit normality.

\section{Socket Usage}

Three participants rejected the socket after fitting and alignment because of pain at the socket trimlines (Figure 2). A fourth participant rejected the socket after $3 \mathrm{~d}$ because of distal pain, whereas another became deceased. The remaining participants ( $n=8)$ used the prosthesis over a period of $167 \pm 1 \mathrm{~d}$ and indicated regular use throughout this period. Descriptive statistics (mean $\pm \mathrm{SD}$ ) for these participants were as follows: age $=46.8 \pm 17.1 \mathrm{yr}$; height $=$ $1.65 \pm 0.09 \mathrm{~m}$; amputation duration $=27.4 \pm 12.3 \mathrm{yr}$.

\section{Physical Function}

The descriptive statistics for the physical function tests $(n=8)$ before and after the usage period are listed in Table 2. Following the usage period, the 6MWT significantly increased by $59.8 \pm 28.9 \mathrm{~m}(p=0.001)$, whereas the TUG decreased by $1.7 \pm 2.0 \mathrm{~s}$.

\section{Gait}

No significant changes were found before and after the usage period $(n=8)$ for gait speed, cadence, step length (both sides), stride length, support base, and percent gait cycle (\%GC) times. Although not significant, gait speed and cadence increased by $4.5 \pm 9.1 \mathrm{~cm} \mathrm{~s}^{-1}$ and $3.9 \pm 4.9$ steps $\mathrm{min}^{-1}$, respectively. On average, absolute temporal measures of stance (both sides), double support (both sides) and step (prosthetic side) decreased by $25 \pm 25 \mathrm{~ms}(p<0.05$ ).

\section{Satisfaction}

The satisfaction score $(n=8)$ increased by 5.4 percent $(\mathrm{SD}=12.8 \%)$ after the usage period (Table 2 ). The participants agreed to being "generally satisfied with the prosthesis" before and after the usage period. On the day of fitting, five of the participants were in "total" agreement with the statement, whereas three were in "rather" agreement. Following the usage period, six of the participants were in "total" agreement, whereas two were in "rather” agreement.

\section{DISCUSSION}

This study investigated whether the low-cost and lowskill dependent PCAST can be used to successfully fit TT 


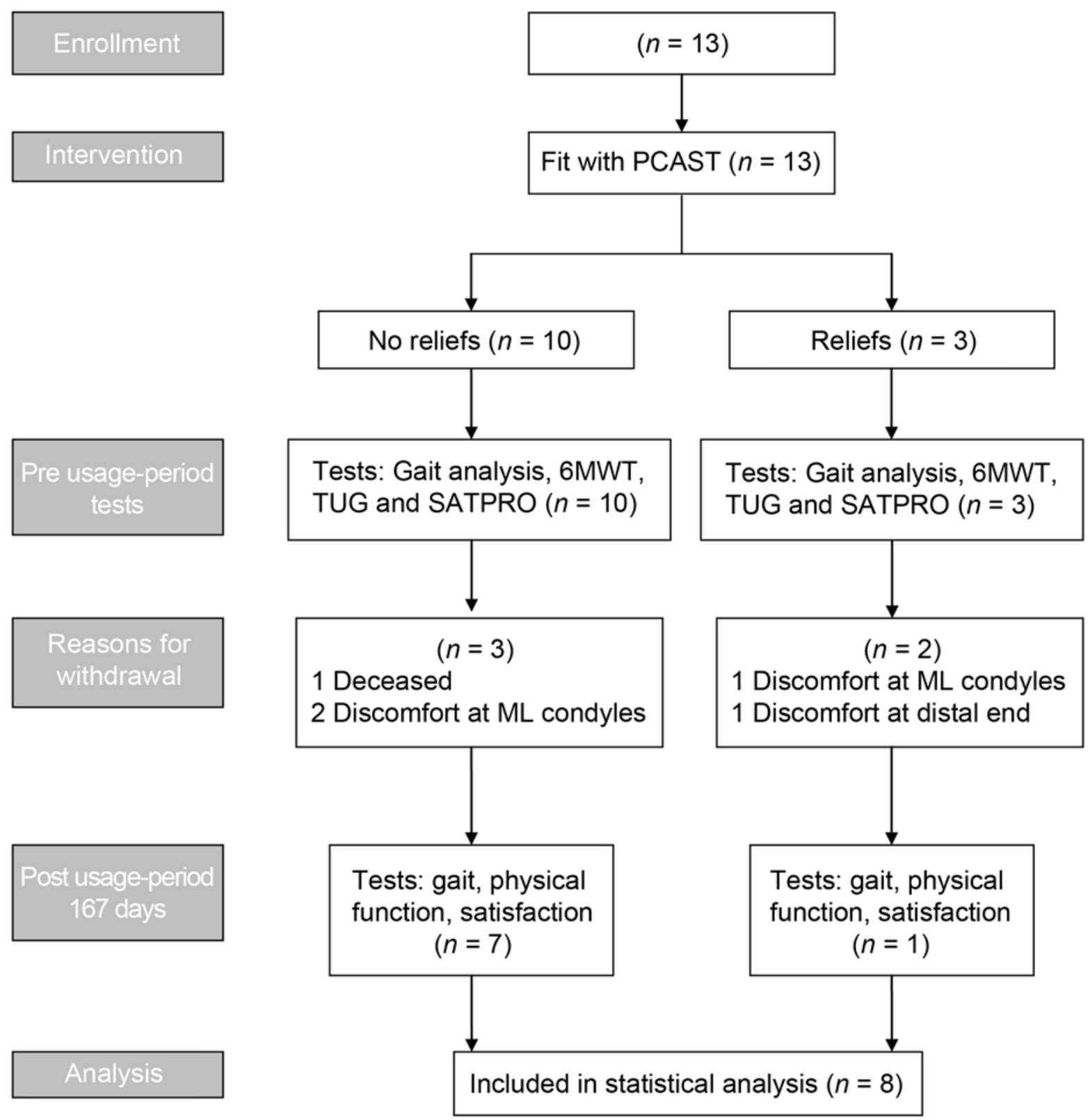

Figure 2.

CONSORT (Consolidated Standards of Reporting Trials) diagram showing participant recruitment, loss to follow-up, and follow-up. $6 \mathrm{MWT}=$ six-minute walk test, $\mathrm{ML}=$ mediolateral, $\mathrm{PCAST}$ = pressure cast, SATPRO = Satisfaction with Prosthesis Questionnaire, TUG $=$ timed up-and-go.

prosthetic sockets in a developing country. The success of the PCAST socket fit was determined by measures of the participants’ physical function, gait, and satisfaction.

\section{Function}

The 6MWT improved after the extended usage period $(p=0.001)$. The 6MWT performances of participants clas- sified as K2 $(n=2)$ and K3 $(n=6)$ ambulators were $320.5 \pm$ 57.8 and $338.8 \pm 69.0 \mathrm{~m}$, respectively, which are better than distances [13] reported for a North American sample (age $58.0 \mathrm{yr}$ ) with unilateral TT and transfemoral amputation classified as K2 (189.9 $\pm 111.3 \mathrm{~m}, n=43)$ and K3 (298.6 \pm $102.4 \mathrm{~m}, n=67$ ) ambulators. The TUG performance before and after the usage period was 10.9 and 9.2 s, respectively, 
Table 2.

Descriptive statistics for physical function and basic gait parameters before (pre) and after (post) pressure cast (PCAST) transtibial socket usage $(n=8)$. Data shown as mean \pm standard deviation.

\begin{tabular}{|c|c|c|c|}
\hline \multirow{2}{*}{ Variable } & \multicolumn{2}{|c|}{ PCAST } & \multirow{2}{*}{ p-Value } \\
\hline & Pre & Post & \\
\hline Step Count & $33.4 \pm 11.9$ & $42.6 \pm 12.0$ & 0.24 \\
\hline Speed $(\mathrm{cm} / \mathrm{s})$ & $88.5 \pm 11.9$ & $93.0 \pm 17.8$ & 0.21 \\
\hline Cadence (steps/min) & $94.3 \pm 6.8$ & $98.2 \pm 10.8$ & 0.06 \\
\hline 6MWT (m) & $272.3 \pm 58.9$ & $332.0 \pm 61.5$ & $0.001^{*}$ \\
\hline TUG (s) & $10.9 \pm 2.3$ & $9.2 \pm 1.6$ & 0.05 \\
\hline SATPRO (\%) & $75.9 \pm 11.7$ & $81.1 \pm 16.5$ & 0.30 \\
\hline \multicolumn{4}{|l|}{ Prosthetic Limb } \\
\hline Step Length (cm) & $55.9 \pm 4.8$ & $56.2 \pm 5.3$ & 0.82 \\
\hline Stride Length (cm) & $112.4 \pm 9.0$ & $113.3 \pm 11.3$ & 0.74 \\
\hline Support Base (cm) & $11.5 \pm 2.5$ & $10.7 \pm 2.5$ & 0.19 \\
\hline Swing Time (\%) & $39.4 \pm 3.3$ & $39.8 \pm 2.7$ & 0.47 \\
\hline Stance Time (\%) & $60.6 \pm 3.3$ & $60.3 \pm 2.7$ & 0.47 \\
\hline Single Support (\%) & $34.1 \pm 3.1$ & $34.7 \pm 2.7$ & 0.22 \\
\hline Double Support Time (\%) & $26.9 \pm 3.8$ & $26.2 \pm 3.5$ & 0.12 \\
\hline Step Time (ms) & $643 \pm 45$ & $621 \pm 53$ & $0.01^{*}$ \\
\hline Stride Time (ms) & $1274 \pm 92$ & $1234 \pm 125$ & 0.05 \\
\hline Swing Time (ms) & $501 \pm 42$ & $489 \pm 49$ & 0.25 \\
\hline Stance Time (ms) & $773 \pm 84$ & $745 \pm 93$ & $0.04^{*}$ \\
\hline Single Support (ms) & $433 \pm 33$ & $425 \pm 34$ & 0.44 \\
\hline Double Support Time (ms) & $345 \pm 69$ & $326 \pm 72$ & $0.01^{*}$ \\
\hline \multicolumn{4}{|l|}{ Intact Limb } \\
\hline Step Length (cm) & $56.3 \pm 5.7$ & $56.9 \pm 7.9$ & 0.64 \\
\hline Stride Length (cm) & $112.2 \pm 8.3$ & $113.3 \pm 11.0$ & 0.66 \\
\hline Support Base (cm) & $11.6 \pm 2.7$ & $11.0 \pm 2.6$ & 0.30 \\
\hline Swing Time (\%) & $33.9 \pm 2.7$ & $34.6 \pm 2.7$ & 0.09 \\
\hline Stance Time (\%) & $66.1 \pm 2.7$ & $65.4 \pm 2.7$ & 0.09 \\
\hline Single Support (\%) & $39.3 \pm 3.6$ & $39.7 \pm 2.6$ & 0.51 \\
\hline Double Support Time (\%) & $26.7 \pm 3.6$ & $26.0 \pm 3.3$ & 0.08 \\
\hline Step Time (ms) & $634 \pm 61$ & $614 \pm 81$ & 0.13 \\
\hline Stride Time (ms) & $1279 \pm 86$ & $1236 \pm 123$ & 0.06 \\
\hline Swing Time (ms) & $433 \pm 33$ & $425 \pm 34$ & 0.44 \\
\hline Stance Time (ms) & $846 \pm 79$ & $810 \pm 103$ & $0.02^{*}$ \\
\hline Single Support (ms) & $501 \pm 42$ & $489 \pm 49$ & 0.25 \\
\hline Double Support Time (ms) & $344 \pm 68$ & $324 \pm 69$ & $0.02^{*}$ \\
\hline
\end{tabular}

which is similar to the TUG performance (7.94 \pm 1.59 and $7.37 \pm 1.33 \mathrm{~s}$ ) of a similarly aged cohort of Italian TT amputees (age $44.9 \pm 9.5, n=10$ ) fitted with two different passive vacuum suspension systems [12]. These times are also better than the TUG times of $17.8 \pm 16.7$ and $18.1 \pm$
19.0 s reported by Gordon et al. [13] for an older group of 60 Australians with TT amputation who were categorized as being in the public (age $63.4 \pm 18.3 \mathrm{yr}$ ) or private health systems (age $63.2 \pm 13.9 \mathrm{yr}$ ). These findings show that participant function was relatively high. It is reasonable to propose, therefore, that the PCAST was relatively successful for the eight participants who remained in the study.

\section{Gait}

Spatial and normalized temporal gait measures (\%GC) remained unchanged after the usage period $(n=8)$. Although significant changes $(p<0.05)$ in nonnormalized temporal measures (e.g., step, stance, and double support time) were found, these differences ( $\approx 25 \mathrm{~ms}$ ) were not considered to have clinical relevance. Interestingly, the participants exhibited a high degree of step length symmetry between the prosthetic and intact limbs on both test occasions, whereas the asymmetry between the normalized temporal measures (\%GC) of swing, stance, and single support remained. These findings show that gait patterns were essentially unchanged, further supporting the success of the PCAST.

\section{Satisfaction}

On both test occasions, the SATPRO scores $(n=8)$ showed a relatively high level of satisfaction compared with scores reported by Gordon et al. [13] for respective public $(60.8 \% \pm 8.1 \%)$ and private $(61.8 \% \pm 9.1 \%)$ health system cohorts. This outcome, in conjunction with the 100 percent general satisfaction, further supports the success of the PCAST.

\section{PCAST Socket}

The PCAST may result in the need to create reliefs in the socket to reduce forces acting on pressure-intolerant areas such as the distal tibial end, tibial ridge, fibular head, femoral condylar, and tibial condylar areas of the socket. Three of the thirteen participants required socket reliefs that were highly localized (Table 1, Figure 2). The reliefs were introduced after verbal feedback given by these participants. The prosthetists created the reliefs by softening the socket with a heat gun and expanding the volume by pushing with simple tools. The reliefs were able to remove the discomfort immediately, allowing the participants to continue with the trial. However, two of the three participants rejected the socket during the usage period and were lost to follow-up (Figure 2). Interestingly, the sites of discomfort that caused the 
rejection for these two participants were different from the sites that required reliefs during initial fitting (preusage period). This indicated that reliefs were effective at relieving initial discomfort but could lead to other high pressure areas in the residual limb. It also highlighted the complexity that could arise from rectifying the PCAST socket fit.

The PCAST produced comfortable sockets for a wide variety of residual limb shapes. Both short and long bony residual limbs, as shown in Figure 3, have been fitted successfully with the PCAST. Identifying suitable patients for PCAST fitting and documenting clear guidelines for its use will be the focus of future studies.

In this study, cuff suspension was used. For shorter residual limbs or residual limbs with unstable knees, supracondylar type suspension is preferred where the socket extends above and over the femur condyles, enabling an anatomical grip as well as some mediolateral control of the knee joint. However, this suspension requires active socket modification above the condyles. Though possible with the PCAST, such modification was not performed because it requires considerable skill on the part of a prosthetist. Instead, the trimline of the socket

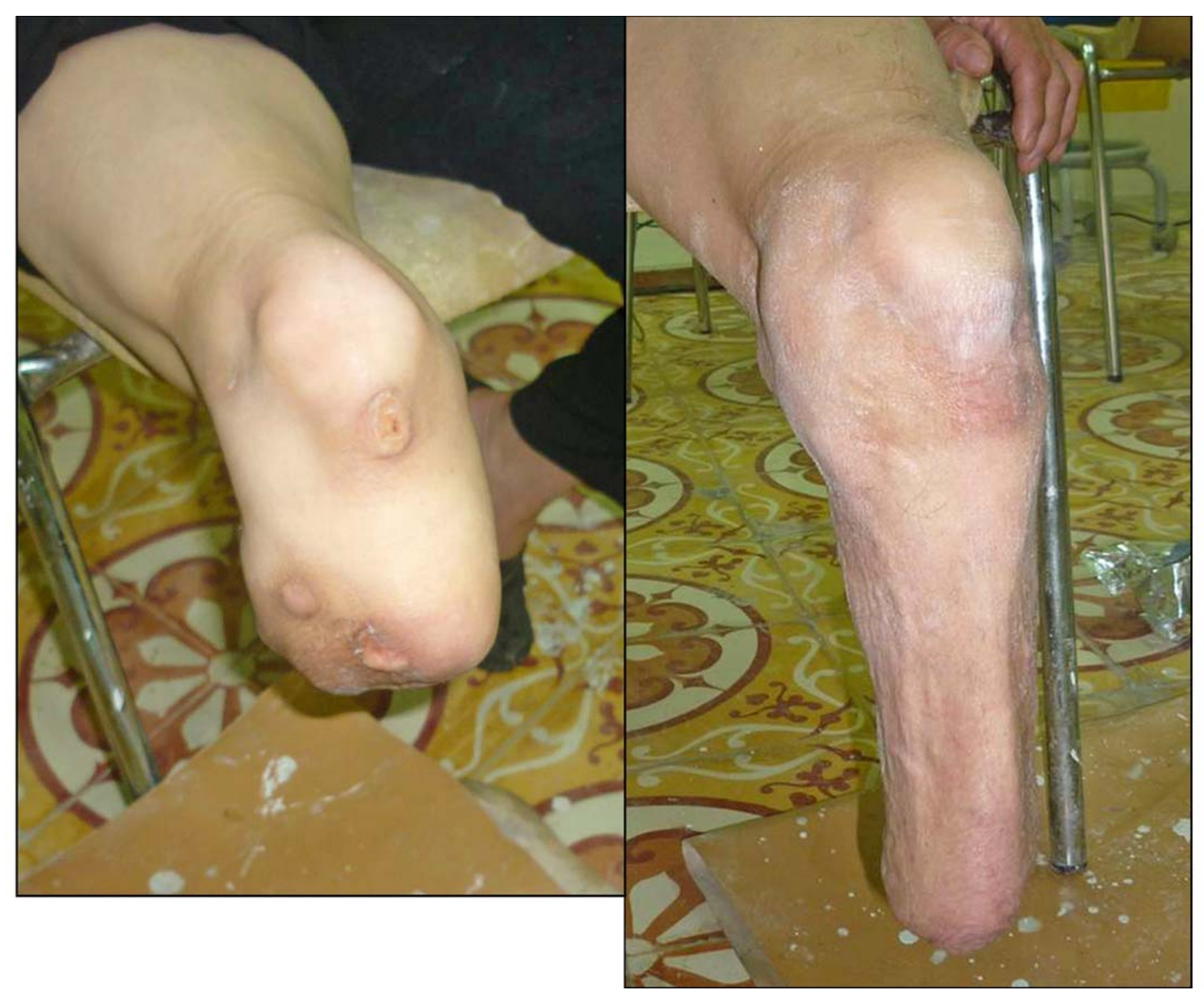

Figure 3.

Residual limb shapes including short stump and long bony stump that were successfully fitted using pressure casting technique. 
was kept as high as possible or just below the epicondyles of the femur so as to provide mediolateral control about the knee joint.

Four of the thirteen participants rejected the PCAST during the usage period (Figure 2). Through observation and participant feedback, it was evident that the socket was too small for three of these participants. Essentially, it forced the residual limb to "sit out" of the socket, causing pain at the socket trimlines. The replacement of the cotton sock used during the casting process with a thin stocking did not overcome this problem. This issue may have arisen from volume changes in the residual limb during the wait period between casting and fitting. It is important to note that the PCAST creates an "intimate" fit for the residual limb during standing. As such, there is little leeway for volume changes. This may be overcome by casting with a thicker sock, which would allow some adjustment during fitting. However, further studies will be needed to show that casting with a thick sock will not create problems to other parts of the residual limb that can benefit from the PCAST's intimate fit. The fourth participant to reject the socket experienced distal pain. Upon postusage presentation, distal packing was removed to increase the socket length, which seemingly alleviated the issue.

Finally, it must be acknowledged that cultural idiosyncrasies in prosthetic use may have influenced this study. Many factors, including cultural attitudes toward life and society, may account for the low attrition rate in this study. The investigation of these factors was beyond the scope of this study.

\section{Limitations}

There were several limitations to this study. Firstly, the design precluded socket blinding. Secondly, the omission of questions from the initial SATPRO analysis may have affected its validity; however, given that scores are calculated as a percentage of possible maximum points, we believe the omission or inclusion of these questions did not render the scores incomparable, but rather allowed for a more relevant representation of the participants' satisfaction. Another limitation was the small sample size and the loss of five participants to follow-up. A further possible limitation was the decision not to record the participants' satisfaction, function, and gait with their original prosthesis. The overarching purpose of the study, however, was to determine the potential of this technique in a developing country and not to compare different socket types. Moreover, this study had no control over the quality of the origi- nal socket and prosthesis and therefore comparisons with the PCAST were considered inappropriate. Finally, we had no control over how much the participants used the prosthesis over the $167 \pm 1 \mathrm{~d}$. Nonetheless, the participants indicated regular use over this period.

\section{CONCLUSIONS}

The PCAST sockets were successfully fitted and used by 8 of the 13 participants over a period of $167 \pm 1 \mathrm{~d}$. This shows that the technique can be used to fabricate and successfully fit TT prosthetic sockets in conjunction with low-cost prosthetic components in a developing country. In summary, high satisfaction scores were found after the initial fit and extended usage period. The 6MWT showed significant improvement, whereas spatial and normalized temporal gait measures remained unchanged after the usage period. This shows the PCAST can produce a comfortable and functional socket for people with unilateral TT amputation in a developing country.

\section{ACKNOWLEDGMENTS}

\section{Author Contributions:}

Study concept and design: P. V. S. Lee, N. Lythgo.

Acquisition of data: N. Lythgo, S. Laing.

Analysis and interpretation of data: P. V. S. Lee, N. Lythgo, S. Laing, J. Lavranos.

Drafting of manuscript: P. V. S. Lee, N. Lythgo, S. Laing, J. Lavranos, N. H. Thanh.

Critical revision of manuscript for important intellectual content:

P. V. S. Lee, N. Lythgo.

Statistical analysis: N. Lythgo, S. Laing.

Obtained funding: P. V. S. Lee, N. Lythgo.

Administrative, technical, or material support: P. V. S. Lee, N. H. Thanh. Study supervision: P. V. S. Lee, J. Lavranos, N. H. Thanh.

Financial Disclosures: The authors have declared that no competing interests exist.

Funding/Support: This material was based on work supported by the CASS (Contributing to Australian Scholarship and Science) Foundation (Melbourne, Victoria, Australia) and the Richmond Rotary Club (Richmond, Victoria, Australia).

Additional Contributions: The authors wish to thank Mr. Dao Hong Duc and Mr. Pham Hung Cuong from the VIETCOT for their contributions to the study. The authors also wish to thank Mr. John Corcoran from JC Measurements P/L (Australia) for kindly supplying a GAITRite instrumented walkway for the study.

Institutional Review: Ethics approval was obtained from the University of Melbourne (Australia) and the University of Labour and Social Affairs (Vietnam). Written informed consent was obtained from participants. 
Participant Follow-Up: The authors do not plan to inform participants of the publication of this study. However, participants have been encouraged to check the University of Melbourne, CASS Foundation, and Rotary Club Richmond Web sites for updated publications.

\section{REFERENCES}

1. Nielson C. A survey of amputees: Functional level and life satisfaction, information needs, and the prosthetist's role. J Prosthet Orthot. 1991;3(3):125-29.

2. Datta D, Vaidya SP, Alsindi ZS. Analyses of prosthetic episodes in trans-tibial amputees. Prosthet Orthot Int. 1999; 23(1):9-12. [PMID:10355638]

3. Nair A, Hanspal RS, Zahedi MS, Saif M, Fisher K. Analyses of prosthetic episodes in lower limb amputees. Prosthet Orthot Int. 2008;32(1):42-49. [PMID:17943622] http://dx.doi.org/10.1080/03093640701610615

4. Murdoch G. The Dundee socket for below knee amputation. Prosthet Int. 1965;3:12-14.

5. Goh JC, Lee PV, Chong SY. Stump/socket pressure profiles of the pressure cast prosthetic socket. Clin Biomech (Bristol, Avon). 2003;18(3):237-43. [PMID:12620787] http://dx.doi.org/10.1016/S0268-0033(02)00206-1

6. Thanh NH, Poetsma PA, Jensen JS. Preliminary experiences with the CIR casting system for transtibial prosthetic sockets. Prosthet Orthot Int. 2009;33(2):130-34. [PMID:19367516] http://dx.doi.org/10.1080/03093640802676457

7. Goh JC, Lee PV, Chong SY. Comparative study between patellar-tendon-bearing and pressure cast prosthetic sockets. J Rehabil Res Dev. 2004;41(3B):491-501.

[PMID:15543467] http://dx.doi.org/10.1682/JRRD.2004.03.0491

8. MEDICARE. Medicare region $C$ durable medical equipment prosthetics orthotics supplier (DMEPOS) manual. Columbia (SC): Palmetto GBA; 2005.

9. Day HJ. A review of the consensus conference on appropriate prosthetic technology in developing countries. Prosthet Orthot Int. 1996;20(1):15-23. [PMID:8740072]

10. Jensen JS, Heim S. Evaluation of polypropylene prostheses designed by the International Committee of the Red Cross for trans-tibial amputees. Prosthet Orthot Int. 2000;24(1): 47-54. [PMID:10855438] http://dx.doi.org/10.1080/03093640008726521

11. Resnik L, Borgia M. Reliability of outcome measures for people with lower-limb amputations: Distinguishing true change from statistical error. Phys Ther. 2011;91(4):555-65.

\section{[PMID:21310896]}

http://dx.doi.org/10.2522/ptj.20100287

12. Brunelli S, Delussu AS, Paradisi F, Pellegrini R, Traballesi M. A comparison between the suction suspension system and the hypobaric Iceross Seal-In ${ }^{\circledR}$ X5 in transtibial amputees. Prosthet Orthot Int. 2013;37(6):436-44.

[PMID:23436696]

http://dx.doi.org/10.1177/0309364613476531

13. Gordon R, Magee C, Frazer A, Evans C, McCosker K. An interim prosthesis program for lower limb amputees: Comparison of public and private models of service. Prosthet Orthot Int. 2010;34(2):175-83. [PMID:20184499] http://dx.doi.org/10.3109/03093640903510980

14. Gailey RS, Roach KE, Applegate EB, Cho B, Cunniffe B, Licht $S$, Maguire M, Nash MS. The amputee mobility predictor: An instrument to assess determinants of the lowerlimb amputee's ability to ambulate. Arch Phys Med Rehabil. 2002;83(5):613-27. [PMID:11994800]

15. Miff SC, Childress DS, Gard SA, Meier MR, Hansen AH. Temporal symmetries during gait initiation and termination in nondisabled ambulators and in people with unilateral transtibial limb loss. J Rehabil Res Dev. 2005;42(2):175-82. [PMID:15944882] http://dx.doi.org/10.1682/JRRD.2004.03.0038

16. Bilodeau S, Hébert R, Desrosiers J. [Questionnaire on the satisfaction of persons with lower-limb amputations towards their prosthesis: Development and validation]. Can J Occup Ther. 1999;66(1):23-32. French. [PMID:10462879] http://dx.doi.org/10.1177/000841749906600103

17. Bilodeau S, Hébert R, Desrosiers J. Lower limb prosthesis utilisation by elderly amputees. Prosthet Orthot Int. 2000; 24(2):126-32. [PMID:11061199] http://dx.doi.org/10.1080/03093640008726535

Submitted for publication April 15, 2013. Accepted in revised form June 26, 2013.

This article and any supplementary material should be cited as follows:

Lee PV, Lythgo N, Laing S, Lavranos J, Thanh NH. Pressure casting technique for transtibial prosthetic socket fit in developing countries. J Rehabil Res Dev. 2014;51(1): 101-10. http://dx.doi.org/10.1682/JRRD.2012.10.0191

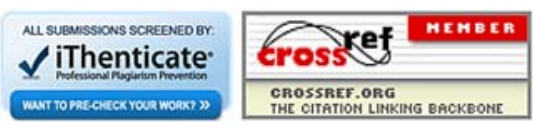

